\title{
Retocolite ulcerativa ou colite por citomegalovírus em paciente portador de doença renal crônica em hemodiálise: um desafio diagnóstico
}

\author{
Juliana Felizardo Viana ${ }^{1}\left(\mathbb{D}\right.$, Daniella Bezerra Duarte ${ }^{1,2,3,4}$ (D) Cynthia Paes Pereira ${ }^{2}$ (D), Maria Carolina \\ Santa Rita Lacerda ${ }^{1,2}$ (D), Yara Janaina Porto Ribeiro ${ }^{1,2}$ (D) , Flora Braga Vaz ${ }^{1,2}$ (D), Rodrigo Peixoto \\ Campos $^{1,2,3,4} \mathbb{E}$
}

\section{RESUMO}

A retocolite ulcerativa $(\mathrm{RCU})$ é um distúrbio intestinal inflamatório crônico que acomete o cólon e o reto, com patogênese associada a distúrbios imunológicos e tratamento baseado em imunossupressão. O sistema imune de pacientes em hemodiálise (HD) é suprimido pelo meio urêmico e o uso de imunossupressores pode levar a infecções oportunistas, como citomegalovírus (CMV). A infecção por CMV pode levar a recaída ou alterar o curso da RCU. $\mathrm{O}$ presente artigo relata o caso de um paciente do sexo masculino, 42 anos, portador de doença renal crônica (DRC) sem etiologia definida, em HD há seis anos, sem nenhuma intercorrência clínica até então, que apresentou um quadro grave de pancolite, com diagnóstico endoscópico e histopatológico inicial de RCU, evoluiu com refratariedade ao tratamento clínico, sendo submetido à colectomia total e ileostomia, tendo a análise microscópica da peça cirúrgica revelado além de processo inflamatório crônico, a presença de atipias em células endoteliais sugestivas de infecção viral por CMV, confirmada por imunohistoquímica, com melhora clínica após tratamento com ganciclovir. Os achados desse paciente enfatizam a importância de considerar a possibilidade de RCU e colite por CMV como diagnóstico diferencial nos pacientes com DRC em HD que apresentam febre e diarreia sanguinolenta, especialmente naqueles que não respondem ao tratamento clínico inicial.

Palavras-chave: Retocolite ulcerativa, Citomegalovírus, Doença renal crônica, Colectomia. 


\section{INTRODUÇÃO}

A retocolite ulcerativa (RCU) é um distúrbio intestinal inflamatório crônico que afeta principalmente o cólon e o reto e possui patogênese associada a distúrbios imunológicos. O quadro clínico de indivíduos portadores de RCU inclui dor abdominal, diarreia sanguinolenta, urgência e tenesmo e a evolução clínica é dependente da atividade da doença ${ }^{1}$.

Indivíduos portadores de doença renal crônica (DRC) terminal raramente são diagnosticados com RCU. A supressão imunológica ocasionada pelo meio urêmico poderia torná-los menos susceptíveis a desenvolver uma associação entre estas doenças ${ }^{1}$. Tal associação, sobretudo naqueles que apresentam refratariedade ao tratamento clínico da RCU, pode favorecer o surgimento de infecções oportunistas, a exemplo da infecção causada pelo citomegalovírus $(\mathrm{CMV})^{2}$. Por outro lado, a diferenciação entre um surto de RCU e um episódio de colite por CMV verdadeiro se constitui num desafio na prática clínica ${ }^{3}$.

O presente artigo tem por objetivo relatar um caso de um paciente portador de DRC em terapia hemodialítica com diagnóstico inicial de RCU e subsequente diagnóstico de colite por CMV. Sua importância se dá por haver uma rara descrição na literatura da associação dessas doenças em pacientes com DRC, assim como também pela severidade do quadro clínico de abertura.

\section{RELATO DE CASO}

Paciente do sexo masculino, pardo, 42 anos, portador de doença renal crônica (DRC) em hemodiálise (HD) há seis anos, sem etiologia definida, admitido no nosso hospital por apresentar quadro de febre e diarreia mucossanguinolenta persistente, iniciado três dias antes da admissão. $O$ paciente havia sido diagnosticado com DRC seis anos antes, tendo entrado em terapia dialítica ao diagnóstico. Evoluiu nesse período sem intercorrências clínicas, até o quadro atual. A princípio, foi tratado para uma provável infecção intestinal com antibioticoterapia oral (ciprofloxacino e metronidazol) e albendazol. Após três dias do uso das medicações, persistiu com febre e piora do quadro diarreico, além de sinais de septicemia, sendo transferido para uma unidade de terapia intensiva onde foram coletadas amostras sanguíneas e de fezes para culturas e trocado o antibiótico para piperacilina-tazobactam.

Os resultados das hemoculturas e coproculturas foram negativos, bem como três amostras do exame parasitológico de fezes. Devido à persistência do quadro diarreico e piora clínica, foi submetido à colonoscopia com achados característicos de RCU moderada em atividade, pancolite (Figura 1), cujos espécimes obtidos por biópsia apresentaram acentuada proctite crônica agudizada erosiva e microabscessos crípticos.

Diante do diagnóstico endoscópico de RCU, iniciou uso de corticosteroide (via endovenosa) e mesalazina (vias oral e retal), sem melhora clínica, mantendo cerca de 20 evacuações diárias. Foi associada azatioprina, também sem resposta. Devido ao quadro de pancolite refratária à conduta clínica, 36 dias após a admissão foi submetido a tratamento cirúrgico com a realização de colectomia total e ileostomia.

A análise microscópica da peça cirúrgica revelou um processo inflamatório crônico agudizado associado a atipias em células endoteliais sugestivas de infecção viral por citomegalovírus (CMV) e a análise imunohistoquímica confirmou a infecção viral (Figura 2). Realizou exame sorológico para CMV, sendo detectada IgG positiva e IgM negativa. $O$ teste sanguíneo quantitativo para CMV através de PCR (reação em cadeia de polimerase) revelou a presença de 180 cópias $/ \mathrm{mL}$ do vírus. Fez uso do antiviral ganciclovir por via endovenosa, evoluindo com melhora do quadro clínico. Durante todo o período de internação hospitalar, apresentou perda ponderal progressiva de mais de $20 \mathrm{~kg}$, caracterizando um quadro de desnutrição grave. Iniciou dieta parenteral total que atingia $58 \%$ de suas necessidades nutricionais e posteriormente dieta mista (parenteral mais via oral) acrescida de suplementação nutricional, apresentando boa evolução clínica e nutricional.

\section{DISCUSSÃO}

Relatamos um caso clínico de um paciente do sexo masculino, de 42 anos, portador de DRC sem etiologia definida, em tratamento dialítico há seis anos, sem nenhuma intercorrência clínica até então, que apresentou um quadro grave e refratário de pancolite, recebendo diagnóstico inicial de RCU. A RCU é uma doença inflamatória intestinal (DII) 

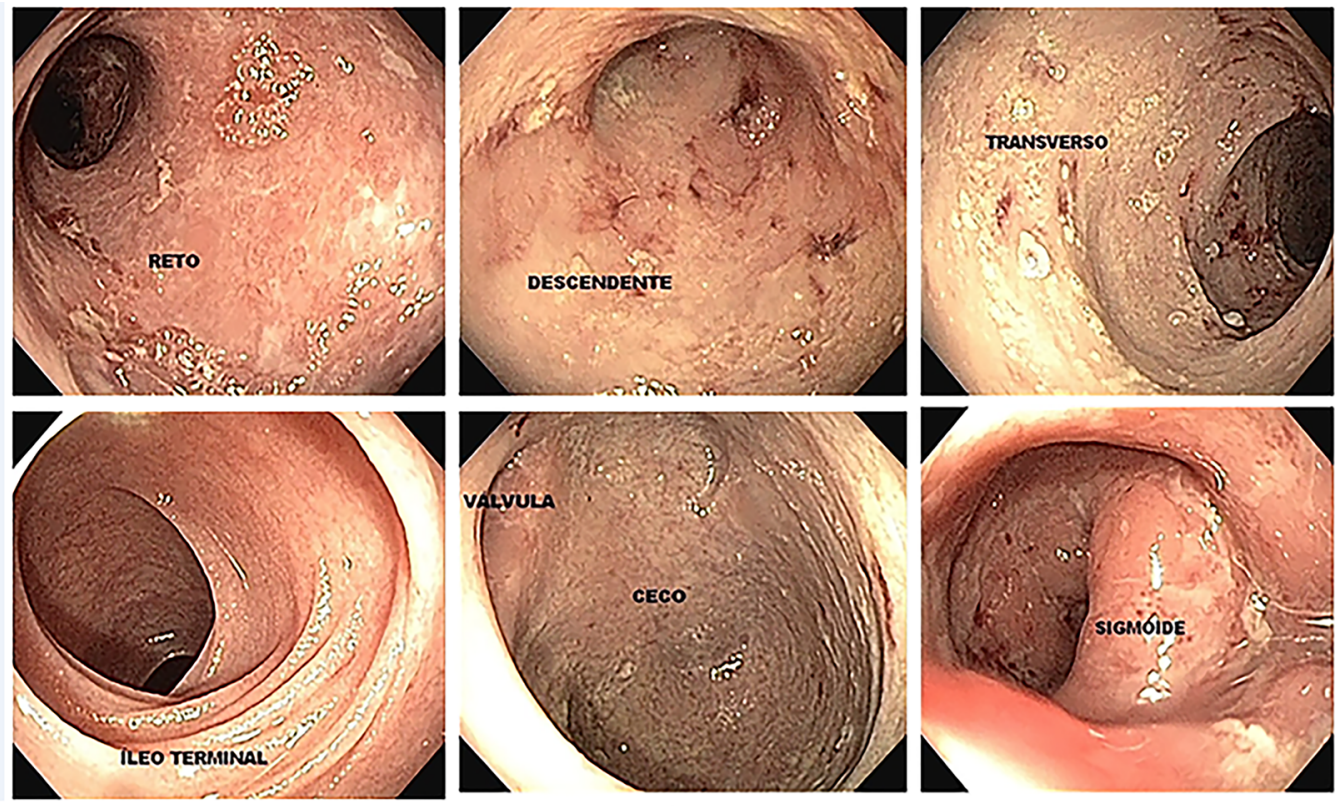

Figura 1 imagens de videocolonoscopia mostrando mucosa do cólon e do reto enantematosa e edemaciada, com aumento da granularidade e diminuição da visualização da vascularização da submucosa. Presença de ulcerações rasas recobertas por fibrina e diminuição das haustrações, conferindo um aspecto tubular ao cólon.
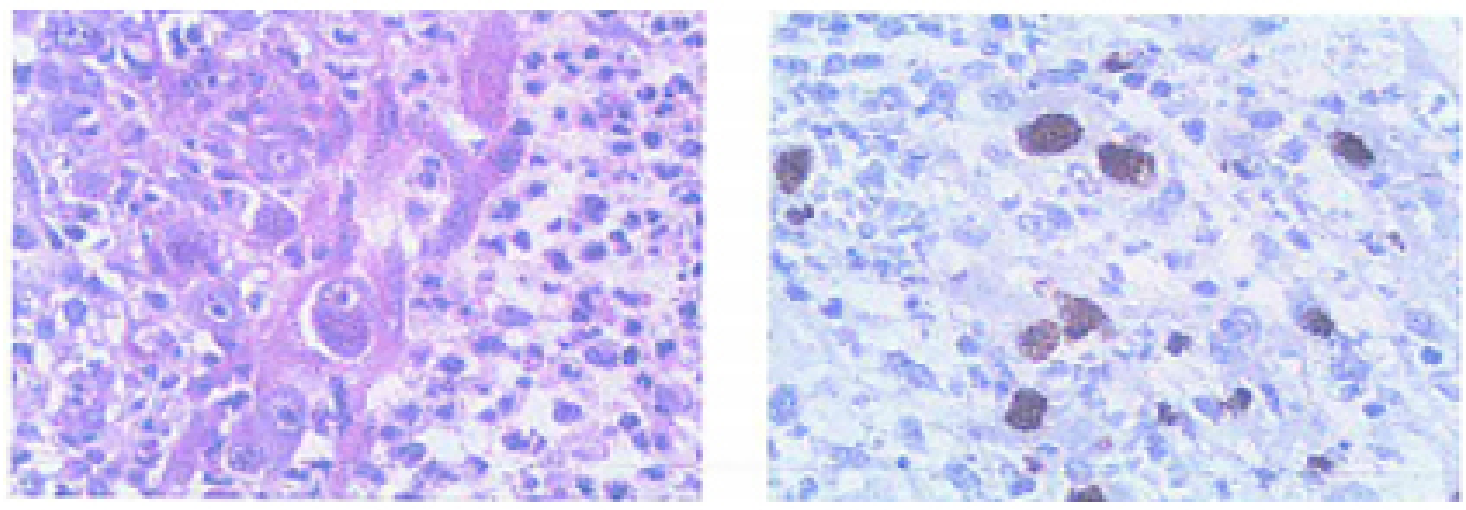

Figura 2 imunohistoquímica positiva para citomegalovírus em espécimes do cólon.

crônica e idiopática, caracterizada por períodos de recidiva e remissão, que envolve a mucosa do reto em $95 \%$ dos casos e pode ser estendida de forma contínua e circunferencial para segmentos proximais do cólon. O pico de idade para o seu desenvolvimento é entre 30 e 40 anos e não há predominância entre os sexos. A taxa de incidência de RCU pode variar de 0,5 a 31,5 por 100.000 pessoas a cada ano, dependendo da população estudada. Frente ao perfil de incidência observado, torna-se importante considerar a influência de fatores ambientais no curso da doença ${ }^{4,5}$.
Os sinais e sintomas da RCU são diarreia, resultante da disfunção colônica em relação à absorção de água e minerais, com gravidade dependente do curso da doença, fezes mucossanguinolentas, tenesmo, dores abdominais, febre, fadiga, anorexia e perda de massa corporal ${ }^{6}$. O estado nutricional do paciente sofre influência direta do quadro clínico da doença ${ }^{7}$. O diagnóstico da RCU é baseado em achados clínicos, laboratoriais, endoscópicos e características histológicas ${ }^{8}$.

A RCU é um distúrbio intestinal que raramente está presente em pacientes com DRC dialítica9,10. 
O sistema imunológico dos indivíduos em hemodiálise é constantemente afetado pelo meio urêmico. Dessa forma, como a resposta imunológica da população dialítica encontra-se atenuada, a atividade da RCU é potencialmente suprimida, isso, por sua vez, pode justificar a associação incomum entre essas doenças ${ }^{11}$.

Nesse contexto, quando ocorre a associação de DRC com doenças cujo tratamento consiste em terapias imunossupressoras, como a $\mathrm{RCU}$, torna o indivíduo mais susceptível ao desenvolvimento de infecções oportunistas, uma vez que a resposta imunológica estará iminentemente comprometida. A infecção viral por citomegalovírus (CMV) é um exemplo de infecção oportunista que pode surgir ${ }^{1}$. Embora haja uma alta soroprevalência de CMV em pacientes com DRC, a doença por CMV nesses pacientes é raramente relatada ${ }^{12}$.

O primeiro relato da associação entre CMV e RCU foi descrito em 1961 por Powell et al. ${ }^{13}$. Desde então, permanece incerto o papel do CMV nesses pacientes, no sentido de que a infecção viral pode exacerbar a DII estabelecida ou se é resultado da reativação em consequência da atividade da DII e do seu tratamento ${ }^{14}$. A prevalência de CMV na DII varia de 1,5 a $4,5 \%$. Entre os pacientes com DII, o CMV é encontrado mais comumente na RCU do que na doença de Crohn, especialmente durante os episódios de colite aguda grave, com uma prevalência de até $40 \%{ }^{15}$.

$A$ reativação do $C M V$ é frequente na $R C U$ grave ou resistente à terapia com corticosteroide. $O$ aumento da proliferação celular no tecido colônico inflamado e ulceroso com RCU ativa exerce um tropismo positivo pelo CMV, atraindo-o para o local; a redução da atividade dos linfócitos $T$ "natural killer" em indivíduos portadores de RCU, bem como o uso de drogas imunossupressoras, surgem como fatores importantes no processo de reativação da infecção por CMV em pacientes com RCU ${ }^{14}$.

A infecção primária por CMV em hospedeiro imunocompetente tem um curso assintomático, contudo, em imunodeprimidos, como portadores de HIV ou doenças crônicas, transplantados, em tratamento com quimioterapia ou terapias imunossupressoras, pode cursar com manifestações sistêmicas graves afetando o trato gastrintestinal, pulmão, retina e fígado ${ }^{3}$. Os principais fatores de risco para a associação entre CMV e RCU em pacientes com DRC, incluem indivíduos com idade superior a 30 anos, com presença de úlcera visualizada em endoscopia e em terapia recente e principalmente refratária a corticosteroides e/ou imunomoduladores ${ }^{2}$.

O paciente do nosso caso não apresentou resposta ao tratamento clínico com doses altas de corticosteroides e azatioprina, tendo que ser submetido ao tratamento cirúrgico. Relatos de casos e séries retrospectivas sugerem que a infecção pelo CMV pode desencadear um surto de RCU refratário ao uso de corticosteroides e piorar o prognóstico da doença, associado ao aumento do risco de megacólon tóxico e intervenção cirúrgica ${ }^{14}$.

A colectomia é um procedimento cirúrgico necessário em até $15 \%$ dos indivíduos com RCU ${ }^{5}$. Estudos populacionais em Estocolmo e Copenhague relataram taxas de colectomia acumuladas em 10 anos de $28 \%$ e $24 \%$, respectivamente. A necessidade de hospitalização no curso da doença prediz um quadro mais agressivo. Estudos mostraram que pacientes com RCU que necessitaram de internação hospitalar, tiveram cinco vezes mais chances de necessitar de colectomia. O risco de hospitalização é maior em pacientes com RCU extensa observada nos primeiros 90 dias de diagnóstico, bem como naqueles com necessidade precoce do uso de corticoesteroides ${ }^{16}$.

O diagnóstico de colite por CMV do paciente só foi feito após a colectomia através dos achados histológicos da peça cirúrgica (hematoxilinaeosina e imunohistoquímica) e posterior pesquisa viral no sangue através de PCR. O diagnóstico de CMV é classicamente baseado na identificação histopatológica de células infectadas por vírus ou antígenos do CMV em tecidos biopsiados usando hematoxilina-eosina ou imunohistoquímica ${ }^{14}$. O método padrão ouro para diagnosticar a infecção intestinal por CMV é através da pesquisa do vírus a partir de biópsias intestinais através de $\mathrm{PCR}^{17}$. A PCR realizada na mucosa colônica apresenta alta sensibilidade ( $93 \%$ a $96,7 \%$ ) e especificidade $(93 \%$ a $98,7 \%$ ), sendo útil no diagnóstico de infecção por CMV em casos suspeitos e que tenham apresentado coloração histoquímica negativa, além disso, um resultado positivo pode estar associado a um pior prognóstico da doença ${ }^{14,18}$.

O diagnóstico diferencial entre RCU e colite por CMV se constitui num desafio na prática clínica. Ambos compartilham características clínicas semelhantes, incluindo febre, mal-estar, diarreia, 
hematoquezia, dor abdominal e perda de peso. Embora alguns achados endoscópicos sejam mais comuns em pacientes com colite por CMV, como úlceras perfuradas, não há características patognomônicas confiáveis na endoscopia que possam distinguir entre as duas condições ${ }^{3}$. A possibilidade do nosso paciente ter apresentado quadro de colite aguda grave por CMV que não foi diagnosticada e tratada precocemente é possível, no entanto, não foram identificados achados típicos de colite por CMV na avaliação histológica dos espécimes obtidos através da colonoscopia realizada no início do quadro, aliado ao fato da prevalência de colite por CMV ser elevada durante os episódios de colite aguda grave da $\mathrm{RCU}^{15}$ e da prevalência de colite por CMV em pacientes com Doença Renal Crônica ser baixa ${ }^{12}$.

O nosso paciente apresentou perda ponderal expressiva de cerca de $30 \%$ do seu peso corporal. Fez uso de dieta parenteral total e teve boa recuperação nutricional pós-operatória apesar de ter sido submetido à colectomia total e de ter doença renal crônica dialítica. O momento da cirurgia de emergência é de importância crucial para pacientes com RCU, pois o atraso pode levar ao agravamento da condição geral e do estado nutricional do paciente. Além disso, cirurgia de emergência em pacientes anêmicos, nutricionalmente comprometidos, imunossuprimidos e inflamados têm alta morbimortalidade ${ }^{19}$. Terapia nutricional agressiva e correção de desarranjos metabólicos combinados com o acompanhamento clínico rigoroso devem ser instituídos ${ }^{20}$. A necessidade de cirurgia deve ser avaliada com antecedência e recomenda-se a cirurgia precoce no caso de falha no tratamento clínico ${ }^{21}$.

\section{CONCLUSÃO}

Apesar da rara associação de RCU e doença renal crônica, esse diagnóstico deve ser o lembrado nos pacientes que se apresentam com diarreia mucossanguinolenta persistente, podendo ser grave já na apresentação inicial, com necessidade de tratamento cirúrgico. Além disso, e por se tratar de paciente imunossuprimido pela própria doença renal dialítica, a colite por CMV deve ser incluída no diagnóstico diferencial, podendo acontecer de forma isolada ou em associação com a RCU, especialmente nos casos que necessitam de doses altas de corticosteroide. Desta forma, um alto índice de suspeição de RCU e colite por CMV é necessário e, uma vez que o diagnóstico é feito, o tratamento deve ser instituído o mais precoce possível para melhorar o desfecho desses pacientes.

\section{REFERÊNCIAS}

1. Yamada S, Kanazawa Y, Nakamura N, Masutani K, Esaki M, Kitazono T, Tsuruya K. Ulcerative Colitis Presented as Fever and Bloody Diarrhea at Initiation of Dialysis in an Elderly Patient with End-Stage Kidney Disease. Case Rep Med. 2015;2015. doi:10.1155/2015/725205.

2. Armstrong $\mathrm{MJ}$, Thomas T, Iqbal T, Boulton R, Goh J. Protracted severe systemic cytomegalovirus disease in an immunosuppressed patient with ulcerative colitis. Frontline Gastroenterol. 2018;9(2):143-147. doi:10.1136/flgastro-2017-100889.

3. Mourad FH, Hashash JG, Kariyawasam VC, Leong RW. Ulcerative colitis and cytomegalovirus infection: From A to Z. J Crohn's Colitis. 2020;14(8):1162-1171. doi: $10.1093 /$ ecco-jcc/jjaa036.

4. Da Silva BC, Lyra AC, Rocha R, Santana GO. Epidemiology, demographic characteristics and prognostic predictors of ulcerative colitis. World J Gastroenterol. 2014;20(28):94589467. doi:10.3748/wjg.v20.i28.9458.

5. Ungaro R, Mehandru S, Allen PB, Peyrin-Biroulet $L$, Colombel JF. Ulcerative colitis. Lancet. 2017;389(10080):17561770. doi:10.1016/S0140-6736(16)32126-2.

6. Panaccione R. Mechanisms of inflammatory bowel disease. symptomes and compication. Gastroenterol Hepatol (N Y). 2013;9(8):529-532. http://www.ncbi. nlm.nih.gov/pubmed/24719603\%0Ahttp://www.ncbi. nlm.nih.gov/pubmed/24719603.

7. Głąbska D, Guzek D, Lech G. Nutritional Status of Men with Ulcerative Colitis in Remission in a Pair-Matched Case-Control Study. J Clin Med. 2018;7(11):438. doi: $10.3390 / j \mathrm{~cm} 7110438$.

8. Conrad K, Roggenbuck D, Laass MW. Diagnosis and classification of ulcerative colitis. Autoimmun Rev. 2014;13(4-5):463-466. doi:10.1016/j.autrev.2014.01.028.

9. Kume K, Yamasaki M, Yoshikawa I, Harada M. Infliximab treatment in a patient with Crohn's disease on haemodialysis. Color Dis. 2011;13(3):341-341. doi:10.1111/j.1463-1318.2010.02217.x.

10. Chiba M, Tsuda S, Tsuji T, Nakane K, Komatsu M, Miura Y, Ishida T, Shibahara T, Nishimoto T. Crohn's disease successfully treated with infliximab in a patient receiving hemodialysis: Case report and review of the literature. Med (United States). 2014;93(7):1-4. doi:10.1097/MD.0000000000000054.

11. Kato $S$, Chmielewski M, Honda $H$, Pecoits-Filho $R$, Matsuo S, Yuzawa Y, Tranaeus A, Stenvinkel P, Lindholm $B$. Aspects of immune dysfunction in end-stage renal 
disease. Clin J Am Soc Nephrol. 2008;3(5):1526-1533. doi: 10.2215/CJN.00950208.

12. Chen $Y M$, Hung $Y P$, Huang $C F$, Lee $N Y$, Chen $C Y$, Sung JM, Chang CM, Chen PL, Lee CC, Wu YH, Lin HJ, Ko WC. Cytomegalovirus disease in nonimmunocompromised, human immunodeficiency virus-negative adults with chronic kidney disease. J Microbiol Immunol Infect. 2014;47(4):345-349. doi:10.1016/j.jmii.2013.01.011.

13. Powell RD, Warner NE, Levine RS, Kirsner JB. Cytomegalic inclusion disease and ulcerative colitis. Am J Med. 1961;30(2):334-340. doi:10.1016/00029343(61)90105-X.

14. Garrido E, Carrera E, Manzano R, Lopez-Sanroman A. Clinical significance of cytomegalovirus infection in patients with inflammatory bowel disease. World $\mathrm{J}$ Gastroenterol. 2013;19(1):17-25. doi:10.3748/wjg. v19.i1.17.

15. Yerushalmy-Feler A, Padlipsky J, Cohen S. Diagnosis and Management of CMV Colitis. Curr Infect Dis Rep. 2019;21(2):1-6. doi:10.1007/s11908-019-0664-y.

16. Samuel S, Ingle SB, Dhillon S, Yadav S, Scott Harmsen W, Zinsmeister AR, Tremaine WJ, Sandborn WJ, Loftus E V. Cumulative incidence and risk factors for hospitalization and surgery in a population-based cohort of ulcerative colitis. Inflamm Bowel Dis. 2013;19(9):1858-1866. doi:10.1097/MIB.0b013e31828c84c5.

17. Paul M, Gupta E, Jain P, Rastogi A, Bhatia V. Diagnostic utility of quantitative cytomegalovirus DNA polymerase chain reaction in intestinal biopsies from patients with inflammatory bowel disease. J Lab Physicians. 2018;10(01):038-043. doi:10.4103/JLP.JLP_94_17.

18. Yadegarynia D, Tehrani S, Roohi M, Gachkar L, Nadji SA, Hashemi M, Molanaei S. Prevalence of cytomegalovirus infection in patients with ulcerative colitis: A prospective cross-sectional study in Tehran, Iran. Iran J Microbiol. 2018;10(5):342-347.

19. Pal S, Sahni P, Pande GK, Acharya SK, Chattopadhyay TK. Outcome following emergency surgery for refractory severe ulcerative colitis in a tertiary care centre in India. BMC Gastroenterol. 2005;5(1):39. doi:10.1186/1471230X-5-39.

20. Rombeau JL, Barot LR, Williamson CE, Mullen JL. Preoperative total parenteral nutrition and surgical outcome in patients with inflammatory bowel disease. Am J Surg. 1982;143(1):139-143. doi:10.1016/00029610(82)90144-1.

21. Travis SP, Farrant JM, Ricketts C, Nolan DJ, Mortensen NM, Kettlewell MG, Jewell DP. Predicting outcome in severe ulcerative colitis. Gut. 1996;38(6):905-910. doi:10.1136/gut.38.6.905. 
Autor Correspondente:

Daniella Bezerra Duarte

E-mail: dabedu2@hotmail.com

Editor:

Prof. Dr Felipe Villela Gomes

Recebido: $17 / 07 / 2020$

Aprovado: 18/01/2021 